Erratum

\title{
Erratum: Liu, Z.; Ji, F.; Wang, M.; Zhu, T. \\ One-Dimensional Constitutive Model for Porous \\ Titanium Alloy at Various Strain Rates and \\ Temperatures. Metals 2017, 7, 24
}

\section{Metals Editorial Office}

MDPI AG St. Alban-Anlage 66, 4052 Basel, Switzerland; metals@mdpi.com

Academic Editor: Hugo F. Lopez

Received: 7 March 2017; Accepted: 7 March 2017; Published: 8 March 2017

The Metals Editorial Office wishes to report the following erratum to this paper [1]. In the paper, Figure $4 \mathrm{a}, \mathrm{b}$ is the same as Figure $4 \mathrm{c}$. The correct version of Figure $4 \mathrm{a}, \mathrm{b}$ is as follows:

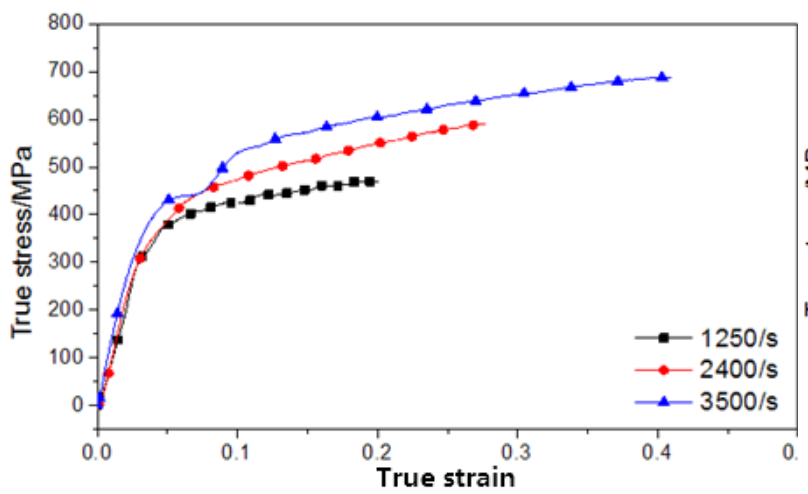

(a)

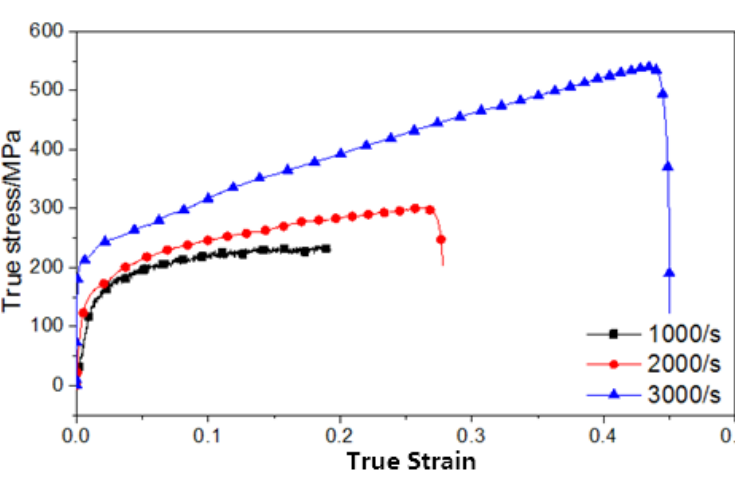

(b)

Figure 4. Stress-strain curves of the porous titanium alloy specimens (porosity: $26 \%$ and $36 \%$ ) at the same temperatures but different strain rates: (a) $\varepsilon_{p}=26 \%, T=25{ }^{\circ} \mathrm{C}$; (b) $\varepsilon_{p}=36 \%, T=25{ }^{\circ} \mathrm{C}$; (c) $\varepsilon_{p}=26 \%, T=100{ }^{\circ} \mathrm{C}$; (d) $\varepsilon_{p}=36 \%, T=100{ }^{\circ} \mathrm{C}$; (e) $\varepsilon_{p}=26 \%, T=200{ }^{\circ} \mathrm{C}$; (f) $\varepsilon_{p}=36 \%, T=200{ }^{\circ} \mathrm{C}$; (g) $\varepsilon_{p}=26 \%, T=300{ }^{\circ} \mathrm{C}$; and (h) $\varepsilon_{p}=36 \%, T=300{ }^{\circ} \mathrm{C}$.

The error was introduced during proofreading by authors. We apologize for any inconvenience caused to the readers by this mistake. The manuscript will be updated and the original will remain online on the article website.

\section{Reference}

1. Liu, Z.; Ji, F.; Wang, M.; Zhu, T. One-Dimensional Constitutive Model for Porous Titanium Alloy at Various Strain Rates and Temperatures. Metals 2017, 7, 24. [CrossRef]

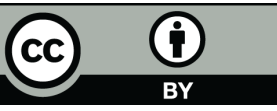

(C) 2017 by the author. Licensee MDPI, Basel, Switzerland. This article is an open access article distributed under the terms and conditions of the Creative Commons Attribution (CC BY) license (http:/ / creativecommons.org/licenses/by/4.0/). 